\title{
Material Too Soft or Flexible
}

National Cancer Institute

\section{Source}

National Cancer Institute. Material Too Soft or Flexible. NCI Thesaurus. Code C133507.

Problem associated with the device material that results in the material's inability to

maintain the desired shape or support function. 